\title{
Determination of gestational age: correlation between foetal biometry and transverse cerebellar diameter in women with uncomplicated pregnancy
}

\author{
Pavithra S. N. ${ }^{1}$, Vimala D. ${ }^{1}$, Prema Priya G. ${ }^{1}$, Shankar R. ${ }^{2 *}$
}

\begin{abstract}
${ }^{1}$ Department of Obstetrics and Gynecology, ${ }^{2}$ Department of Preventive Medicine, Vinayaka Mission Kirupananda
\end{abstract} Variyar Medical College and Hospital, Salem, Tamil Nadu, India

Received: 08 June 2017

Accepted: 29 June 2017

\section{*Correspondence:}

Dr. Shankar R.,

E-mail: shnkr_radhakrishnan@yahoo.com

Copyright: (c) the author(s), publisher and licensee Medip Academy. This is an open-access article distributed under the terms of the Creative Commons Attribution Non-Commercial License, which permits unrestricted non-commercial use, distribution, and reproduction in any medium, provided the original work is properly cited.

\section{ABSTRACT}

Background: Transverse Cerebellar Diameter (TCD) serves as a reliable predictor of gestational age in foetus and is a standard against which aberrations in other foetal parameters can be compared, especially when the GA cannot be determined by the date of last menstrual period or early pregnancy scan, TCD is one foetal parameter that has remained consistently superior in predicting gestational age in both singleton and twin gestation. Aim of the study was to assess and evaluate the effectiveness of transverse cerebellar diameter by using ultrasonography for determining the gestational age of the foetus.

Methods: A cross-sectional study was done in 100 uncomplicated pregnant patients between the 15th week of gestation to term referred from routine antenatal clinic in outpatient and in-patient department of Obstetrics and Gynecology department of Vinayaka Mission Krupananda Variyar medical college and hospital, Salem during study period April 2015-March 2016. TCD is obtained in the axial plane in the cerebellar view i.e. with a slight rotation of the transducer approximately $30^{\circ}$ from the conventional thalamic plane where the biparietal diameter is measured using the cavum septi pellucidi, third ventricle and thalami as landmarks.

Results: The correlation of transcerebellar diameter (TCD) with that of BPD (bi-parietal diameter) had shown a perfect positive correlation $(r=0.978)$ and a similar type of correlation was also seen with HC (head circumference) $(\mathrm{r}=0.979)$, AC (abdominal circumference) $(\mathrm{r}=0.966)$, FL (femur length) $(\mathrm{r}=0.976)$ and USG GA (ultrasonogram gestational age) $(\mathrm{r}=0.983)$.

Conclusions: In the normally developing foetus, the TCD increases in a linear fashion with advancing gestational age. The data of this study suggest foetal TCD on ultrasound is a reliable predictive biometric parameter of gestational age.

Keywords: Gestational age, Transverse cerebellar diameter, Ultrasonogram

\section{INTRODUCTION}

Determination of intrauterine gestational age by ultrasound in obstetrics plays an important role in management of pregnancy and evaluation of foetal developments. Extremes of foetal growth contribute disproportionately to overall perinatal morbidity and mortality. In last two decades had seen a tremendous progress in application of ultrasound as a diagnostic modality revolutionizing towards better management and care. ${ }^{1}$ This is particularly due to its non-invasive and nonionizing nature leading to wider acceptability. The safety record of diagnostic ultrasound is probably an important reason that it has become so widely used. ${ }^{2}$ Ultrasound is 
safe for the patient and the foetus. There is no reported risk of ionizing radiations as in X-rays, or any other known biological or teratogenic effect. ${ }^{3}$ It is not associated with any harm to early foetal life, growth and vision or hearing during development in childhood and as such no adverse side effects have been observed till today in neurological development and subsequent school performance of the children exposed to ultrasound. ${ }^{4,5}$

Sonographic measurement of foetal biparietal diameter is accepted predictor of gestational age as well. ${ }^{6,7}$ However there is a high variability in the calculated gestational age which increases as pregnancy progresses with maximum difference approximating 3.6 weeks in the third trimester. ${ }^{8,9}$ The estimation of gestational age from individual parameters like the $\mathrm{HC}, \mathrm{AC}$, and $\mathrm{FL}$ also shows a similar variability. Using all the above parameters this variability can be reduced by $25 \%$ to $30 \%$. There are conditions like multiple gestation, dolichocephaly, brachycephaly, microcephaly and intrauterine growth restriction (IUGR) that can alter the shape of the foetal skull which in turn can affect the BPD and increase the variability. ${ }^{10}$

Transverse Cerebellar Diameter (TCD) serves as a reliable predictor of gestational age in foetus and is a standard against which aberrations in other foetal parameters can be compared, especially when the GA cannot be determined by the date of last menstrual period or early pregnancy scan, TCD is one foetal parameter that has remained consistently superior in predicting gestational age in both singleton and twin gestation. ${ }^{11}$ Establishment of normative cerebellar measurements allows for the estimation of gestational age that is independent of abnormal skull shapes of cranial vault due to extrinsic pressure as occurring in dolichocephaly or brachycephaly, foetal growth restriction, multiple pregnancy and offers potential for evaluation of abnormal foetal growth and anomalous development of the central nervous system. ${ }^{12,13}$ As of today very few studies in India had highlighted the importance of measuring transverse cerebellar diameter in determining the gestational age of the foetus, so this study was done to prove the validity of TCD in assessing the foetal gestational age.

Aim of the study was to assess and evaluate the effectiveness of transverse cerebellar diameter by using ultrasonography for determining the gestational age of the foetus.

\section{METHODS}

A cross-sectional study was done in 100 uncomplicated pregnant patients between the $15^{\text {th }}$ week of gestation to term referred from routine antenatal clinic in outpatient and in-patient department of Obstetrics and Gynecology department of Vinayaka Mission Krupananda Variyar medical college and hospital, Salem during study period April 2015-March 2016. Pregnant mothers of any age and any parity with more than 15 weeks of pregnancy till term were included for the study. Mothers with irregular menstrual cycles, unknown or inaccurate last menstrual period, oligohydramnios, polyhydramnios, GDM, overt diabetic, hypertension complicating pregnancy, heart disease complicating the pregnancy, anemia complicating the pregnancy, pre-eclampsia / eclampsia and foetus with IUGR are excluded from the study. The study was undertaken after getting the clearance from the institutional ethical committee.

PNDT form i.e. form $\mathrm{F}$ is obtained from all the pregnant patients. All relevant clinical history was obtained and the LMP was noted. An ultrasonography was performed with pregnant patient in supine position. Good acoustic coupling was obtained using synthetic ultrasound gel. Obstetric ultrasonographies were performed using esoateMy Lab Seven ultrasound scanner using a $3.5 \mathrm{MHz}$ convex probe. Images were recorded in the thermal films using the digital camera. In all the pregnant patients following parameters were obtained. They are BPD, HC, AC, FL, TCD, foetal heart rate, estimated foetal weight, AFI and placental position.

TCD is obtained in the axial plane in the cerebellar view i.e. with a slight rotation of the transducer approximately $30^{\circ}$ from the conventional thalamic plane where the biparietal diameter is measured using the cavum septi pellucidi, third ventricle and thalami as landmarks. In this plane posterior fossa with cerebellum is visualized. The cisterna magna is just posterior to the cerebellum. This plane provides the widest transcerebellar diameter.

Gestational age for the measured TCD is obtained from the reference chart Predicted menstrual age for transverse cerebellar diameter of $14 \mathrm{~mm}$ to $56 \mathrm{~mm} .{ }^{14} \mathrm{TCD} / \mathrm{AC}$ ratio was calculated according to the following formula: $\mathrm{TCD} / \mathrm{AC}$ ratio (\%): TCD (mm)/AC (mm) x 100.

\section{Statistical analysis}

The data are entered and analysed by using SPSS version 21. Mean and standard deviation were derived for all the parametric and continuous variables. Pearson Correlation technique used to test the direction and strength of the relationship between TCD and gestational age and also the various other parameters measured through ultrasound.

\section{RESULTS}

Table 1 shows the age and trimester wise distribution of the study population. It is seen from the table that majority of the antenatal mothers were in the age group of 21-25 years and the minimum age was 18 and the maximum age was 35 with a mean age of 23.5 years. It was also seen that the distribution of age group was almost equal in both the second and third trimester. More than $50 \%$ of the antenatal mothers were primi and about $44 \%$ of them were having one child and only $4 \%$ of the mothers had 2 children (Table 2). 
Table 1: Age and trimester wise distribution of the study population.

\begin{tabular}{|lllllll|}
\hline Age in years & Second trimester & Third trimester & Total & \\
\hline$<20$ & Frequency & $\mathbf{\%}$ & Frequency & $\mathbf{\%}$ & Frequency & $\mathbf{\%}$ \\
\hline $21-25$ & 9 & 19.6 & 14 & 25.9 & 23 & 23 \\
\hline $26-30$ & 28 & 60.8 & 28 & 51.9 & 56 & 56 \\
\hline $31-35$ & 6 & 13.1 & 11 & 20.3 & 17 & 17 \\
\hline Total & 3 & 6.5 & 1 & 1.9 & 4 & 4 \\
\hline Mean age \pm SD & 46 & 100 & 54 & 100 & 100 & 100 \\
\hline
\end{tabular}

Table 2: Parity wise distribution of the study population.

\begin{tabular}{|lllll|}
\hline \multirow{2}{*}{ Parity } & \multicolumn{2}{l}{ Second trimester } & \multicolumn{2}{l|}{ Third trimester } \\
& Frequency & \% & Frequency & \% \\
\hline Primi & 26 & 52.2 & 26 & 51.9 \\
\hline P1 & 22 & 43.5 & 22 & 44.4 \\
\hline P2 & 2 & 4.3 & 2 & 3.7 \\
\hline Total & 50 & 100 & 50 & 100 \\
\hline
\end{tabular}

Considering the weight of the antenatal mothers $90 \%$ of them had a normal BMI and only $3 \%$ of them were overweight and $6 \%$ were underweight (Table 3 ).

Table 3: Distribution of the study population according to their BMI.

\begin{tabular}{|lll|}
\hline BMI & Frequency & $\%$ \\
\hline Severely malnourished & 1 & 1 \\
\hline Underweight & 6 & 6 \\
\hline Normal & 90 & 90 \\
\hline Overweight & 3 & 3 \\
\hline Total & 100 & 100 \\
\hline
\end{tabular}

The correlation of transcerebellar diameter (TCD) with that of BPD (bi-parietal diameter) had shown a perfect positive correlation $(\mathrm{r}=0.978)$ and a similar type of correlation was also seen with HC (head circumference) ( $r=0.979)$, AC (abdominal circumference) $(r=0.966)$, FL (femur length) $(r=0.976)$ and USG GA (ultrasonogram gestational age) $(r=0.983)$.

Table 4: Correlation coefficient of TCD with CGA, BPD, HC, AC and FL.

\begin{tabular}{|lll|}
\hline Variables & Beta co-eficient & P value \\
\hline Constant & 4.143 & 0.25 \\
\hline TCD gestational age & 0.982 & 0.0001 \\
\hline Height & -0.021 & 0.428 \\
\hline Weight & 0.008 & 0.758 \\
\hline
\end{tabular}

TCD also had a perfect positive correlation with the clinical gestational age $(r=0.968)$ (Table 4). It is also proven that there exists a perfect linear regression between TCD and estimation of gestational age by other parameters through ultrasonogram $\left(r^{2}=0.967\right)($ Table 5).
Table 5: Linear regression analysis between TCD gestational age and USG gestational age.

\begin{tabular}{|lll|}
$\begin{array}{|ll|}\text { Combination of } \\
\text { parameters }\end{array}$ & $\begin{array}{l}\text { Pearsons correlation } \\
\text { coefficient }\end{array}$ & P value \\
\hline TCD Vs CGA & 0.968 & $<0.0001$ \\
\hline TCD Vs BPD & 0.978 & $<0.0001$ \\
\hline TCD Vs HC & 0.979 & $<0.0001$ \\
\hline TCD Vs AC & 0.966 & $<0.0001$ \\
\hline TCD Vs FL & 0.976 & $<0.0001$ \\
\hline
\end{tabular}

So, it clearly proves that TCD can exactly predict the gestational age of the foetus similar to the other parameters like BPD, AC and FL but the major advantage is that it can be used in the conditions that alter the shape of the foetal skull and in conditions like IUGR.

\section{DISCUSSION}

According to the recent data from UNICEF globally about 800 women die every day because of preventable causes related to pregnancy and childbirth and in this $20 \%$ of deaths are from India. To achieve an uneventful gestation with a healthy mother and baby particularly in extremes of foetal growth, it is very important to determine the gestational age and the expected date of delivery in a more accurate manner which would eventually determine the management, with regards to mode of delivery either in the form of planned induction of labour or for caesarean section. In countries like India where large numbers of antenatal mothers are unaware of LMP and its importance it is very much essential to assess the gestational age through ultrasonography. Conventional ultrasound biometry like BPD, FL, and HC are nonspecific with limitations in setting of inconsistency between clinical and USG age. These parameters are also influenced by foetal growth, configuration of skull and external compressive forces as in certain abnormal presentations. ${ }^{14}$

Transcerebellar diameter (TCD) represents an independent biometric parameter as shown in this study. The foetal cerebellum visualized as early as $10-20$ postmenstrual weeks. It grows in a linear pattern in the second trimester but the curve flattens in third trimester. ${ }^{15,16}$ Cerebellum is not liable to change in form 
and size because of dense surrounding petrous ridges and occipital bone. ${ }^{16}$ Due to this, TCD can be used where it is difficult to measure BPD or in cases where there are variations in size and shape of head. TCD in millimeters has been shown to correlate with gestational age in weeks upto 24 weeks. Normograms have been established for TCD and gestational age throughout pregnancy. ${ }^{17}$

In this prospective study of 100 pregnant women a perfect linear relationship was found during the second (13 weeks to 28 weeks) and third (29 weeks to term) trimester between the cerebellar growth and the gestational age in weeks. The relationship of foetal cerebellar growth and gestational age is statistically significant. Similar to present results, foetal studies have demonstrated the close relationship between the TCD and gestational age with linear growth of the TCD during the second trimester. ${ }^{11}$ The measurement of TCD in the foetus continues to be a useful indicator for gestational age even in the presence of abnormal skull shapes foetal growth restriction multiple pregnancies and large-fordates foetuses. ${ }^{18}$ Therefore, the TCD measurement of the foetus is resistant to these effects on other foetal measurements.

McLeary et al have found on ultrasonography of the foetal skull that the posterior fossa is not affected by the pressure effects, and the cerebellar diameter is more accurate reflection of gestational age than the biparietal diameter particularly in the presence of abnormal skull shapes like brachycephaly or dolicocephaly. ${ }^{20}$ Montenegro during a routine ultrasound examination of 178 normal pregnant women at 17-24 weeks performed several biometric measurements and stated that TCD seems to be good marker for determining gestational age when compared to other biometric parameters and a similar type of results were also quoted by Strizhova in his study. ${ }^{20,21}$

Hata and Hata studied the ultrasonographic measurements of the cerebellum and found that it decreased in small for date babies, but was normal in large for date babies and he proposed ultrasonic cerebellar diameter has a perfect linear relationship with the gestational age. ${ }^{22}$ Mikovic and Markovic et alstudied the growth of foetal cerebellum in normal pregnancy between 20 and 40 weeks and he proposed that TCD can be practically used for determining the gestational age of the foetus wherever measuring BPD seems to be difficult and unsuitable due to moulding of the head. ${ }^{23}$

Campbell studied 162 measurements of the TCD and abdominal circumference obtained between 15-38 weeks of gestation. ${ }^{24}$ The mean ratio between the TCD and abdominal circumference remained constant and proved that it was gestational age independent. Guan generated a nomogram for TCD with respect to gestational age and compared foetal TCD, biparietal diameter, head circumference, abdominal circumference and femur length measurements by ultrasound. ${ }^{25}$ Correlation coefficient between the birth weight and their parameters were studied and concluded that the function of the transverse cerebellar diameter in the evaluation of foetal growth and development is better than any other parameter. Chavez developed a similar nomogram with a special emphasis in the $3^{\text {rd }}$ trimester and stated that TCD had a similar relationship with gestational age across previously published nomogram before 28 weeks. ${ }^{26}$

\section{CONCLUSION}

In the normally developing foetus, the TCD increases in a linear fashion with advancing gestational age. The data of this study suggest foetal TCD on ultrasound is a reliable predictive biometric parameter of gestational age. Nevertheless, the best combination of biometric measurements remains to be determined. We recommend that TCD be used as an important sonographic biometric parameter for accurate prediction of GA.

\section{Funding: No funding sources}

Conflict of interest: None declared

Ethical approval: The study was approved by the Institutional Ethics Committee

\section{REFERENCES}

1. Callen PW. Ultrasonography in obstetrics and gynecology, 3rd ed. WB Saunders company, Philadelphia; 1994.

2. Nyborg WL. Safety of Medical Diagnostic Ultrasound. InSeminars Ultrasound, CT and MRI. 2002;23(5):377-86.

3. Mahony BS, Callen PW, Filly RA. The distal femoral epiphyseal ossification center in the assessment of third-trimester menstrual age: sonographic identification and measurement. Radiology. 1985;155(1):201-4.

4. Kieler H, Haglund B, Waldenström U, Axelsson O. Routine ultrasound screening in pregnancy and the children's subsequent growth, vision and hearing. BJOG. 1997;104(11):1267-72.

5. Salvesen KA, Vatten LJ, Eik-Nes SH, Hugdahl K, Bakketeig LS. Routine ultrasonography in utero and the subsequent handedness and neurological development. BMJ. 1993;307:159-164.

6. Campbell S. An improved method of foetal cephalometery by ultrasound. J Obstet Gynaecol Brit Cwelth. 1968;75:568-76.

7. Kurtz AB, Wapner RJ, Kurtz RJ, Dershaw DD, Rubin CS. Analysis of biparietal diameter as an accurate indicator of gestational age, JCU. 1980;8:319-326.

8. Sabbagha RE, Hughey M. Standardization of sonar cephalometry and gestational age. Obstet Gynecol. 1978;52:402-6.

9. Hadlock FP, Deter RL, Harrist RB, Park SK. Foetal biparietal diameter: a critical re-evaluation of the relation to menstrual age using realtime ultrasound, JUM. 1982;1:97-104. 
10. Richard D. Mcleary, Lawerence R. Kuhns and Mason Barr Jr. Ultrasonography of the foetal cerebellum. Radiology. 1984;151:439-42.

11. Goldstein I, Reece EA. Cerebellar growth in normal and growth restricted foetuses of multiple gestation. Am J Obstet gynecol. 1995;173(4):1343-8.

12. Co E, Raju TN, O Aldana. Cerebellar dimensions in assesement of gestational age in neonates. Radiology.1991;181:581-5.

13. Reece EA, Goldstein I, Pilu G, Hobbins JC. Foetal cerebellar growth unaffected by intrauterine growth retardation: A new parameter for prenatal diagnosis. Am J Obstet Gynecol. 1987;157:632-8.

14. Sharma G, Ghode R. Foetal transcerebellar diameter and transcerebellar diameter - abdominal circumference ratio as a menstrual age independent parameter for gestational age estimation with grading of cerebellar maturity. Int $\mathrm{J}$ Reprod Contracept Obstet Gynecol. 2015;4(6):2036-40.

15. Julia AS, Hamzeiou KS, Rajagopalan V, Kim K, Barkovich AJ, Habas PA et al. 3D morphometric analysis of human foetal cerebellar development. In: Julia AS, Hamzeiou KS, Rajagopalan V, editors. The cerebellum. Philadelphia: Mosby;2012:761-70.

16. Kuklisova M, Aljabar P, Srinivasan L, Counsell SJ, Doria V, Serag A et al. A dynamic 4D probabilistic atlas of the developing brain. Neuroimage. 2011;54:2750-63.

17. Baschat AA. Foetal growth disorders. In: Baschat AA, editor. High risk pregnancy. St. Louis: Saunder;2011:173-9.

18. Sinnatamby CS. Last's Anatomy Regional and Applied. Central Nervous System. 10th ed. New York: Churchill Livingstone;2000:479-81.

19. McLeary RD, Kunhs LR, Barr M, Ultrasonography of the foetal cerebellum. Radiology. 1984;151:43942.
20. Monotenegro NA, Leite LP. Foetal cerebellar measurements in second trimester ultrasonographyclinical value. J Perinat Med. 1989;17:365-9.

21. Strizhova NV, Elamin HY, Bokin IS. The ultrasound diagnosis of intrauterine foetal growth retardation. Akush Ginekol (Mosk). 1992;30-1.

22. Hata K, Hata $T$, Senoh D. Ultrasonographic measurement of the foetal cerebellum in utero Gynecol Obstet Invest. 1989;28:111-2.

23. Mikovic Z, Markovic A, Dukic M, Pazin V. Growth of the foetal cerebellum in normal pregnancy. Jugost Ginekol Perinatol. 1989;29:157-60.

24. Campbell WA, Nardi D, Vintzileos AM, Rodis JF, Turner GW, Egan JF. Transverse cerebellar diameter/abdominal circumference ratio throughout pregnancy: a gestational age-independent method to assess fetal growth. Obstet Gynecol. 1991;77(6):8936.

25. Guan B. Surveillance of foetal growth and foetal cerebellar transverse diameter by ultrasonographic measurement. Zhonghua Yi Xue Zhi. 1992;72:65-7.

26. Chavez MR, Ananth CV, Smulian JC, Lashely S, Konotopouls EV, Vintzileos AM. Foetal transcerebellar diameter nomogram in singleton gestations with special emphasis in the third trimester: A comparison with previously published nomograms. J Obstet Gynecol. 2003;189:1021-5.

Cite this article as: Pavithra SN, Vimala D, Priya GP, Shankar R. Determination of gestational age: correlation between foetal biometry and transverse cerebellar diameter in women with uncomplicated pregnancy. Int J Reprod Contracept Obstet Gynecol 2017;6:3599-3603. 